\title{
Accountability and Relationship-Definition Among Food Banks Partnerships
}

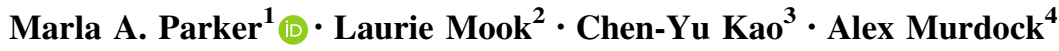

Published online: 11 September 2019

(C) The Author(s) 2019

\begin{abstract}
Food pantries typically operate in a partnership structure where they are primarily supported by a larger food bank. However, the ability to execute that mission through cooperative arrangements greatly depends upon accountability, a key dynamic that ensures partners are fulfilling expectations and key roles. This exploratory study utilizes qualitative interview data $(n=61)$ from a large food bank network to understand the extent to which a lead agency (i.e., a large food bank) meets expectations of accountability among partners. The interview results demonstrate that the extent to which expectations are met relate to different types of relationships between the lead agency and partner members. Furthermore, the ways in which partners assess the strengths or weaknesses of the food bank's accountability reveal different types of relationships within the network, namely that of suppliercustomer, supporter-customer, and supporter-collaborator.
\end{abstract}

Marla A. Parker

Mparke17@calstatela.edu

Laurie Mook

Lmook@asu.edu

Chen-Yu Kao

Ckao8@asu.edu

Alex Murdock

alex.murdock@1sbu.ac.uk

1 Department of Political Science, California State UniversityLos Angeles, Los Angeles, USA

2 School of Community Resources and Development, Arizona State University, Phoenix, USA

3 Center for Organization Research and Design, Arizona State University, Phoenix, USA

4 London South Bank University, London, UK
Keywords Accountability · Network relationships · Collaboration · Partnership · Food banks

\section{Introduction}

As food insecurity rates increase and transcend low-income socioeconomic boundaries, food banks and pantries are being called upon to play a more prominent role in addressing issues of hunger (Curtis and McClellan 1995; Bazerghi et al. 2016). These organizations have been the subject of increased research interest not just in the USA but also in Europe (Baglioni et al. 2017; González-Torre et al. 2017). They find themselves faced with nearly unprecedented circumstances emerging from constrained economic conditions resulting in increased poverty rates and associated outcomes such as poor health, educational attainment, and social stability (Berner et al. 2008). Rapidly expanding client demand and strains on capacity leading to running out of food are but a few of the critical challenges facing food banks (Paynter and Berner 2014).

As such, food insecurity easily lends itself to being classified as a wicked problem and thus benefits from being addressed collaboratively by organizations to increase capacity and address the ancillary issues (Weber and Khademian 2008). Collaborative approaches have become increasingly common to provide comprehensive and efficient public value-particularly in times when resources such as funding may be scarce or threatened (Gardner and Director 2011; Weber and Khademian 2008). Indeed, food pantries generally operate in a partnership structure, which consists of a well-resourced or larger food bank distribution center providing support for mission delivery of other food providers (e.g., smaller food banks or pantries). 
Research affirms the value of nonprofit collaboration to enhance the capacity and resources that may elude individual agencies in their efforts to implement missions (Guo and Acar 2005; Hill and Lynn 2003; Proulx et al. 2014; Snavely and Tracy 2000). Furthermore, studies assert that successful leveraging and implementation of a partnership's capacity and resources depends upon accountability, which is generally defined as participating organizations fulfilling their expected roles and responsibilities (Acar et al. 2008; Broadbent et al. 1996).

Additionally, the multifaceted nature of accountability (e.g., various accountability issues and methods) among nonprofit and public sector collaborations has also been studied (for example, Candler and Dumont 2010; Jordan 2005; Broadbent et al. 1996). However, we find no significant academic work which examined this in the specific unique context of food bank collaborations. Indeed, Canadian legislation passed in 2012, which specifically referred to food bank accountability, appears to have not generated any published and peer-reviewed academic research (McIntyre et al. 2016). A Google Scholar search for research with the specific focus on accountability of food banks conducted in March 2019 also failed to reveal any more recent publications. We conclude that this is an important area of research which has not received a significant degree of attention in terms of academic and published research. Moreover, less research focuses on taxonomies of accountability, particularly within a single network generally geared toward achieving a single general purpose. Thus, an opportunity exists not only to understand how accountability facilitates food bank operations, but in a larger context, how nonprofit collaborations can be strengthened and more efficient based on a variety of expectations.

Food bank partnerships provide an interesting empirical opportunity because while the common goal of mitigating poor food access motivates the establishment and continuity of partnerships between organizations, the extent to which this is the primary goal of each individual organization varies. For example, in addition to smaller food pantries, larger food banks may partner with places such as domestic violence shelters, after school programs, churches and other social service-oriented nonprofits where simply alleviating hunger is not the primary mission (Precious et al. 2017; Sharma et al. 2015). Thus, it is useful to observe how this dynamic is connected to accountability, specifically the expectations that different kinds of partners have of the lead agency (i.e., food bank).

This paper aims to fill the aforementioned gaps by addressing the following research question: How are varying relationship dynamics in a large food bank network related to the perceptions of accountability within that network? To address this question, we take an inductive approach by gleaning insights from interviews of food bank partners asking them to describe the strengths and weaknesses of their relationships. The responses from interviewees revealed that partners within the particular food bank network focus on several issues of strength and weakness: product issues, operational issues, mission-impact issues, and collaboration issues. Additional analysis of the characteristics of the food bank partners led to the development of a taxonomy or model of accountability relationships present within the single network: supplier-customer relationship, supporter-customer relationship, and supporter-collaborator. Lastly, we see a pattern whereby certain issues are connected to various types of accountability relationships, thus implying that even within a single network, the notion of accountability is not singular and thus likely requires varied approaches based on the concern of network members.

Overall, the value of our paper resides in how it lays the groundwork to develop a theory of accountability taxonomies. Additionally, the research can provide insights into how food bank partnerships may likely require various a priori approaches and strategies to ensure accountability based on established relationship type, rather than emergent issues or situations taking place during collaborative activity. As of now, while literature about accountability within public sector networks covers accountability and its role in collaboration (which will be briefly covered below), it lacks depth about types of accountability and how that can inform more strategic approaches. Moreover, typologies or taxonomies of accountability are rarely viewed within the context of a single network. Thus, generally speaking, accountability strategies in a collaborative network may take a one-size-fits-all approach without much respect to other critical variables. The type and nature of a partnership could very well inform expectations of a collaboration, and hence, how accountability is approached and measured as successful or not. This is particularly important, given that single collaborative initiatives may involve many agencies to address a single wicked problem.

The remainder of the paper is organized as follows: First, we provide a brief literature review of collaboration and accountability in networks, and of the emergence of food bank networks. Next, we describe our data source and methods for analyzing accountability within a specific body of food bank partnerships, including an assessment of the lead food bank agency's accountability in certain functional areas by network members. Following this, we report the major themes defining specific types of relationships between the food bank and agencies, as well as how accountability assessments are associated with various relationship types. Finally, we discuss our findings in the context of propositions to provide directions for future 
research for not only the specific context of food banks, but also further understanding network accountability overall.

\section{Literature Review}

Because food banks networks remain generally understudied, a useful starting point is to map their characteristics to known dimensions prevalent in nonprofit partnerships. The benefit of this is threefold: first, it provides insight into the extent food banks networks exhibit relatively well-understood collaboration behaviors and patterns, which can underscore the generalizability of collaboration theory and best practices; second, it can help inform the implementation of specific managerial strategies that can facilitate improved partnerships and collaborations through accountability; and third, it can highlight inconsistencies or gaps in theory as well as best practices. As such, we start with a short overview of collaborations and the importance of collaboration, including its specific application in the context of food banks. Next, we provide a brief history of US food bank and food bank networks, and a more specific description of US food banks models, which emphasizes the nature of accountability within them.

\section{The Need for Network Collaboration}

The increasing complexity and proliferation of social ills, cuts in resources, requirements of funding and oversight organizations, and policy rules have been primary motivators for nonprofits to progressively partner with each other in some form (Chen and Graddy 2010; Sowa 2009). Various models of partnership exist among nonprofits ranging from expansive networks of organizations with long-term (or permanent) dedication to a specific policy space or smaller-scale partnerships created for a specific short-term purpose (Agranoff and McGuire 2004; Proulx et al. 2014; Vernis et al. 2006; Young 2000).

Modes of collaboration include but are not limited to collective impact initiatives, confederations, mergers, movements, public-private partnerships, and strategic alliances involving joint advocacy, programming, or administration (Bartczak 2015; Proulx et al. 2014). Each of these differs according to the degree of involvement of the participants, but is similar in that they have a shared vision and presumably come together to share activities and resources (Barczak 2015). Additionally, connections among agencies may express themselves in a relationship whereby there is not necessarily a mutual exchange of resources, but rather a one-way arrangement whereby an organization supports another operationally in mission execution (Arya and Lin 2007; Guo and Acar 2005).
In the specific context of food banks, the pernicious and complicated nature of food insecurity makes a collaborative approach taken by food banks ideal and even necessary (Booth and Whelan Booth and Whelan 2014; Handforth et al. 2013). Food insecurity relates to a bevy of other social ills including but not limited to public and environmental health, economic barriers, educational access, limited labor opportunities, homelessness and transportation (Jyoti et al. 2005; Schmidhuber and Tubiello 2007; Cook and Frank 2008; Chaparro et al. 2009). The already cited literature provides key examples. For instance, limited employment opportunities that can plague certain socioeconomic brackets results in reduced income, which means reduced ability to purchase necessary food. Yet another example lies in the close connection between food insecurity and educational outcomes, specifically the correlation between reduced nutrition and school performance as well as engagement among students. In areas with little or less than affordable public transportation, access to discounted or free food resources is critical.

Though described further in the section below about the US food bank model, the previously discussed connection between food insecurity and other outcomes means that organizations whose primary missions may not be related to food provision still benefit from engaging in food provision to communities. In other words, by including food delivery as part of programmatic implementation, organizations can facilitate their primary missions. For organizations with a primary mission not related to providing food, the necessity for collaborating with a larger food bank relates to increasing its capacity and scale to serve its users (Sparks et al. 2018; Berner 2017; Weinfield et al. 2014).

\section{Accountability in Networks}

No matter the structure or mode of relationship characterizing networked organizations, successful execution of a shared mission requires accountability. Over the years, various conceptualizations of accountability have formed as knowledge of network governance emerged, but they generally have a few common aspects. First, accountability requires the creation and implementation of processes to ensure that stakeholders fulfill agreed upon roles and expectations (Ebrahim 2003). Second, accountability entails engaging in certain behaviors that facilitate trust and a productive working relationship among network members (Zaheer and Harris 2006). Lastly, accountability encourages implementing rewards, punishments, or corrections for compliant or deviant activity among network members (Ebrahim 2003).

The focus of the presented research uses aspects of the first and second dimensions to conceptualize a meaning of 
accountability to account for how well stakeholders fulfill expected roles and expectations for the purpose of facilitating a productive working relationship. In the context of food bank networks, accountability speaks to how well food banks and their partners fulfill expected roles in order to address the broader issue of food insecurity.

Currently, the landscape of accountability research in collaborative nonprofit management generally focuses on the following areas: different accountability issues encountered in nonprofit collaboration governance, accountability within contracting relationships, mechanisms for and approaches to managing accountability, lines and directions of accountability, power dynamics vis-a-vis accountability structures, role of accountability in governance and accountability based on cross-sectoral relationships. Examples of literature detailing the just mentioned dimensions of network accountability research include Emerson and Nabatchi (2015), Page (2004), Turrini et al. (2010) and Koliba et al. (2011). As suggested, accountability research appears quite exhaustive and nuanced. Also, it is not uncommon to understand accountability based on organizational perceptions, which is what the presented research does.

Nonprofits may find that they can benefit in additional ways from the assets found in other organizations (Austin 2010; Selden et al. 2006). Such assets include but are not limited to capital (human, social, and financial), space, knowledge, and access to other resources (Guo and Acar 2005; Mosley 2010). As such, network members cannot only better implement their primary mission, but can also address important secondary missions. In short, benefits of networked arrangements include increasing capacity and resources, providing more goods and services, enhancing the efficiency of provision, and expanding the breadth of a mission.

To be sure, these benefits do not always come to fruition. In fact, ill-fitting or poorly managed partnerships may not add anything substantive to the value and capacity of the involved organizations (Baker et al. 2011; Gazley 2010a, b; Vernis et al. 2006). In fact, such arrangements can make mission delivery more complicated and consequently less efficient.

Bodies of accountability-centric research in a collaborative context is stronger in certain fields such as emergency management (Kapucu et al. 2010; Waugh and Streib 2006; Kapucu 2005, 2006) and public health (Axelsson and Axelsoon 2006; Mitchell and Shortell 2000). Presumably, value exists in examining various collaboration dynamics (such as accountability) in a specific context. Thus, there is room to understand more in-depth how accountability dimensions manifest in the specific area of food banks, which is a specific understudied dimension of food bank partnership operations (i.e., few food banks studies specifically focus on accountability with robustness). While this is discussed further in the section below describing food bank history and models, it is worthwhile mentioning here that the dependency structure of food banks makes it necessary to study accountability within them (Bazerghi et al. 2016). More specifically, although food banks can and do provide food and assistance directly to community members, they do require partnering with other smaller agencies to do secondary distribution in order to meet their aims of addressing hunger and food insecurity on a larger scale (Bazerghi et al. 2016; Campbell et al. 2013). Thus, mutual dependency in a food bank network is a critical feature, which can make understanding accountability unique. Without accountability, the critical resource provision (e.g., food) is compromised and less than effective. As stated previously, there is an increasing role of food banks as the first line of defense in addressing the plethora of issues related to food insecurity issues, thus having a more in-depth understanding of how key factors make them more less effective is critical.

To provide further context of the food bank landscape that supports the need for specific research of accountability in the food bank landscape as well as highlight related discussion points above, we provide a historical context of food banks and food bank networks as well as further insights into food bank models.

\section{History and Description of Food Bank Networks and Network Accountability}

Food banks are arguably a North American invention (Second Harvest Food Bank of Northwest North Carolina 2015). Food banks are "nonprofit organizations that solicit donations of surplus or salvage foods which they distribute to food pantries, soup kitchens, and other feeding programs' (Curtis and McClellan 1995, p. 99). The idea of food banking is often attributed to John van Hengel in the USA when the first food bank, St. Mary's Food Bank, was set up in Phoenix, Arizona, in 1967. The original idea was to connect surplus and unsaleable food in a wasteful modern society with the needs of the poor and hunger population (Feeding America 2015; Riches 2002). Thus, the original food bank was arguably supply-driven rather than a consequence of demand.

Since then, food banking has evolved into a network, with the establishment of Second Harvest (now Feeding America), a national food bank network organization with around 200 food banks associated with it across the USA, each supplying several hundred food pantry-type organizations (Feeding America 2015). Feeding America is not a government agency but has acquired enormous de facto power. It assigns territories for food banks and enables those food banks to then accredit the suppliers to 
beneficiaries (food pantries) in that area. The food bank can approve (and disapprove) food pantries, and a food pantry seems to have limited rights of appeal or choice in the matter. The food banks are set up as nonprofit corporations, and the food pantries typically also have a similar nonprofit form. Many are linked to churches. There are strong associations with aspects of social justice in the food bank sector which makes for a strong dividing line in ethos with the private sector food industry (Power 1999).

The development of private food assistance networks, including food banks, food pantries, soup kitchens, and emergency shelters, is believed to be related to the failure of public social safety net and social welfare reforms (Curtis and McClellan 1995; Daponte and Bade 2006; Lambie-Mumford 2013; Riches 2002; Tarasuk et al. 2014). In addition, with the increased provision of food industry donations of products which cannot be sold in the market, 'food assistance becomes defined as that which the corporate sector cannot retail' (Tarasuk and Eakin 2005, p. 177). Indeed, for corporations who are directly or indirectly involved in the food business, a food bank can represent an attractive business partner. This typically involves such business partners being represented in the board governance of food banks (Poppendieck 2014). Thus, food banks, in addition to meeting the needs of foodpoor populations, also have an ability to save the food surplus disposal cost and avoid the possible business consequences of offloading a surplus at a cut price. The addition of 'Good Samaritan laws' which encourage such donations makes food banks an attractive option for the food industry (Cohen 2006).

In the USA, a 'food bank' industry has emerged which significantly parallels the regular food industry and indeed utilizes many of the business approaches and trade skills of the food industry (Gundersen et al. 2011, McPherson 2006). This parallel to the food industry is found in the logistical and operational aspects of both Feeding America, its member food banks, and the large number of distribution partners (many called 'food pantries' but also including a range of community-based organizations such as hostels and client-based service organizations (Feeding America 2011). This means that there has been a natural evolution of measures associated with efficiency and in particular of 'supply chain management' (Orgut et al. 2016; Mohan et al. 2013).

A major social welfare program in the USA intended to address various issues associated with poverty is the Food Stamp Program (now known as the Supplemental Nutrition Assistance Program, or SNAP). However, since the Food Stamp Act of 1977, program reform has resulted in the reliance on private food assistance of a significant percentage of the population (Daponte and Bade 2006). Food stamps are not able to provide sufficient food for needy households, and thus, these people usually have to turn to private food assistance to get supplemental food (Berner and O'Brien 2004; Berner et al. 2008; Daponte 2000; Daponte and Bade 2006).

As the need for food assistance increased, so did the growth of the food bank network (Curtis and McClellan 1995). Moreover, along with the passage of the Temporary Emergency Food Assistance Act of 1983 (TEFAP) aimed at distributing surplus farming commodities to the poor, as well as the later constant appropriation of food and administrative funding support, private food assistance has gradually become an institutionalized integral part of the food assistance system in the USA (Curtis and McClellan 1995; Daponte and Bade 2006; Riches 2002.

\section{Food Bank Network Dynamics}

The operation of food bank networks involves many players. Food banks-large warehouses with primary functions of food storage and distribution-are the interface between donors and agencies who serve beneficiaries, between public and private sectors, and between national policies and local community needs (González-Torre and Coque 2016; McEntee and Naumova 2012). Food banks in the USA receive food donations from food and agricultural industries, retailers, government food assistance programs, Feeding America, and sometimes from other food banks. Most of the time food banks distribute the donated food to other nonprofits, namely food banks' partner agencies, which otherwise deal with needy clients directly through either emergency food boxes or on-site meals (Curtis and McClellan 1995). In this sense, the central role of food banks in distributing food and coordinating food needs with partner agencies can be thought of as a model of supply chain management (Larson and McLachlin 2011).

As mentioned previously, food banks' partner agencies are usually small nonprofits or churches, which rely heavily on local volunteers. Being deeply rooted in their neighborhoods and having direct contacts with their clients, partner agencies usually better know clients' needs and can be intermediaries between local needs and larger poverty programs (Daponte 2000).

In addition to distributing food to partner agencies, food banks sometimes act as conveners of community collaboration efforts (McEntee and Naumova 2012; Remley et al. 2013). For example, in order to promote 'choice food pantry models' which 'offer socially acceptable, safe, nutritious foods while providing ancillary assistance services (e.g., supplemental nutrition assistance program, SNAP), and show promise for impacting long-term food security' (Remley et al. 2013, p. 326), the food bank of the Butler County, Ohio, acted as a convener which brought various stakeholders and partners of the local food systems 
to network, collaborate, and discuss food issues as well as facilitated possible resources and ideas sharing. Moreover, it helped partner food pantries overcome capacity barriers in the transition to this new model (Remley et al. 2013; Tarasuk et al. 2014).

At the agency level, characteristics such as organizational capacity are important in determining their ability to respond to clients' needs (Paynter et al. 2011; Paynter and Berner 2014; Tarasuk et al. 2014). As a result, understanding partner agencies' characteristics as manifested in partnerships is important (Paynter et al. 2011). As private food assistance networks become more and more significant as a method to alleviate hunger, partner agencies' perspective on their relationship with their food bank and on their capacity to fulfill service delivery mission is an important area to research, and one to which we contribute with this study.

\section{Data and Methods}

This study uses a case study of a large food bank and its partner agencies to explore accountability relationships (Yin 2014). To conduct our study, we interviewed a random sample of agencies of a large US-based food bank. In particular, we were concerned with how perceptions of strengths and weaknesses of the network aligned with positive and negative aspects of achieving the mission of the food bank. To do this, we used an inductive approach to identify relevant themes common across agencies that relate to collaboration dynamics. The following section describes the case, data sources, and the methods used for analysis in more detail.

\section{Case Study Description}

The food bank that is the subject of this paper operates on a very large scale similar to large private sector food distribution companies. It has large warehouse and cold storage facilities serviced by forklifts to move goods stored on pallets. It runs fleets of large trucks and uses sophisticated tracking mechanisms and computerized logistics. Goods may be moved not just locally but also miles away. Much of the food is sourced industrially as opposed from individual donors. The food bank has a well-established Operations Manual and has to function in a complex regulatory environment which determines what food can be redistributed and, in the context of some government programs, who is eligible.

The partner agencies for the food bank which receive the food are food pantries and social organizations which number in the hundreds. These may involve small 'stores' of food-sometimes in church facilities — where the ability to store perishable food may be limited or even nonexistent. They may open only for a few hours each week. The record keeping may be quite limited and often paper based, and the workers are often on a volunteer basis. What is not sourced via the food bank may well be sourced elsewhere, and what is available depends on what people might give. There is little option to barter or exchange items in surplus for items in shortage.

\section{Data}

Data for this analysis come from semi-structured phone interviews conducted with 61 agencies. The food bank identified these agencies as partners, suggesting a perception of collaboration. A random sample of interviewees was stratified along the dimensions of the partner agency's location (i.e., county), length of relationship with the food bank in years, type of service provided by the agency, and pounds of food received from the food bank. The originally derived random sample contained 70 agencies; however, interviews with nine respondents were not able to be completed due to the inability to reach an agency contact or the agency no longer being part of the food bank network. This resulted in an $87 \%$ response rate. An email invitation was sent to the primary contact of the agency as listed in the food bank's records, and respondents were asked for their voluntary participation in an interview. Follow-up contact was made with the sample agencies to schedule a specific time and date for the interview, which were conducted during February and March 2015.

To understand how the partner agencies perceived the food bank and their relationship with it, the respondents were asked to describe the following: the food bank's mission, the strongest aspect of their relationship with the food bank, and opportunities for improvement or growth in their relationship. Another set of questions asked specifically about the operation of the partner agency. Finally, the respondents were given the opportunity to provide additional feedback about their relationship with the food bank not addressed with the given questions. Interviews were transcribed within $24 \mathrm{~h}$ of the interview, and the transcript provided to the respondent for verification. No changes were requested by the respondents.

\section{Respondent Characteristics}

The following section describes the basic characteristics of the agencies interviewed, which came from the interview questions as well as the sample frame provided by the food bank agency. The majority of the interviewees had midlevel positions within their organizations and were employed for an average of 8.75 years. The range of the length of partnership with the food bank was between two 
and nine years, with an average duration of 6.33 years. This suggests that for the most part, the respondent had relatively full knowledge of the relationship between his or her agency and the food bank. The sample agency's geographic locations and service types were representative of all the hundreds of agencies' locations and service types. Table 1 provides a breakdown of specific service types. Moreover, half of the agencies were geographically proximate to the food bank, while the other half of the agencies were quite dispersed throughout the state and were far away from the food bank. The partner agencies noted having between 20 and 1000 clients.

\section{Method of Analysis}

To analyze the interview transcripts, we took an inductive approach to understanding the nature of the relationships present within the food bank network. Upon receiving all of the interviews, we went through the process of culling various themes from the responses. A qualitative software called HyperRESEARCH was used to code themes related to the primary strengths and opportunities perceived by agencies in terms of their relationship with the food bank. A form of intercoder reliability was performed by ensuring that all interview responses were viewed by at least two team members. This ensured not only consistency among the culled themes, but also allowed for additional themes to be captured. After going through all of the responses, the derived themes were then gathered and reviewed by entire team to identify distinctions and commonalities related to each question.

In total, thirty-eight themes emerged, which were then condensed into four main categories: product-related, operations-related, mission-related, and collaboration. In the identification of strengths related to the relationship, $38 \%$ mentioned the receipt of the food or meals themselves, $21 \%$ mentioned positive aspects of the processes involved in getting the food, $33 \%$ noted mission achievement, and $8 \%$ felt collaboration was the primary strength of the relationship. In terms of opportunities for improvement, $28 \%$ did not have anything to suggest. A quarter of the agencies felt that there were opportunities to improve by better working together with the food bank; $20 \%$ noted improvements to logistics in the way the food bank was run; $15 \%$ made suggestions for improvements to the products provided; and $13 \%$ felt that improvements could be made by focusing on expanding the impact on mission.

\section{Findings}

We present the findings of our analysis in three sections. First, we detail the emergence of three distinct areas of focus as perceived by the food bank agency partners relating to their interactions with the food bank. Second, we propose a model of accountability relationships based on these foci. Third, we use this model to identify factors to predict the characteristics of agencies in each relationship type. Following the findings, we present a number of propositions related to the significance of these results.

\section{Areas of Focus}

Agency and program partners were asked to describe the main area of strength and concern in their relationship with the food bank. Two questions were posed: (1) What do you regard as the strongest aspects of your association with the food bank? And (2) Are there any areas where you feel the partnership could be strengthened, or where there are opportunities for growing the partnership, and how might this happen? The responses to these questions provided the key issue(s) that the agency was concerned with in regard to their interaction with the food bank and thus the area that they felt the food bank was accountable for. In total, thirtyeight categories were identified, which fit into four main themes: product issues, operational issues, mission-impact issues, and collaboration issues (Table 2).

\section{Product Issues}

About $31 \%$ of responses focused on product-related issues. This included the provision of food or meals, the value of the food received because of cost-savings, and access to fresh food, such as produce, meat and dairy products.

Most comments in this area noted that the strength of the food bank was in the products it provided, i.e., food and meals, and sometimes other non-food articles.

Food. We are able to feed our clients and the community. We also receive miscellaneous things such as diapers and hygiene products. When you run or work for a nonprofit organization you value all the help you can get (12 Food program).

Others mention the cost-savings that help them operate and serve more people.

It helps my food budget and helps keep us running. (31 Food program)

We are able to buy food in bulk - about $40-50 \%$ of our food. (30 Food bank) 
Table 1 Characteristics of partner agencies interviewed

\begin{tabular}{lccc}
\hline & Number of respondents & Average pounds of food provided per fiscal year & Average number of clients per month \\
\hline Food banks & 7 & 667,796 & 860 \\
Food pantries & 13 & 158,932 & 423 \\
& & & 49 \\
Food programs & 15 & 6967 & 135 \\
Child nutrition & 4 & 48,806 & 94 \\
Senior centers & 8 & 49,687 & 359 \\
Shelters and residences & 13 & 102,985 & 249 \\
General & 1 & 7648 & 293 \\
Other & 61 & 144,006 & \\
Total & &
\end{tabular}

Table 2 Accountability relationship types

\begin{tabular}{|c|c|c|c|c|}
\hline \multirow[t]{3}{*}{ Relationship type } & \multicolumn{4}{|c|}{ Main focus } \\
\hline & \multicolumn{2}{|c|}{ 'Business' partnership (transactional) } & \multicolumn{2}{|c|}{ 'Social' partnership (transformational) } \\
\hline & Product & Operations & Mission & Collaboration \\
\hline Supplier-customer & $\mathrm{X}$ & $\mathrm{x}$ & & \\
\hline Supporter-customer & $\mathrm{x}$ & $\mathrm{x}$ & $\mathrm{x}$ & $\mathrm{x}$ \\
\hline Supporter-collaborator & & & $\mathrm{x}$ & $\mathrm{x}$ \\
\hline
\end{tabular}

The ability to access food that would not otherwise be available, especially fresh food was noted, although fresh food was an area that agencies would like to see more of, as was more variety in the food provided.

Maybe providing more fresh fruit because they usually just get dry goods. It would be great to have fresh produce. (49 Food pantry)

More variety would help. Seniors ask for more variety. The seniors say it is always the same thing. ( 8 Food program)

We have not been able to pick up fresh fruit and vegetables for two months. The last offer was a truckload of cabbage which was too much to use. It was an all or nothing offer. (1 Food pantry)

\section{Operational Issues}

Almost 23\% of the responses referred to operational factors as the main focus of the relationship. Agencies were looking for fast and flexible service, good communication, helpfulness, and reliability.

The most prevalent issue noted here was communications. While some agencies applauded the food bank for being a good communicator, many more noted this as an area that needed improvement.
One thing I have found is when there is a product issue then they let us know (out of code or a quality issue). I get communications about safety issues. (59 Food program)

I do feel that the dissemination of information goes through many changes of hands. People have changed or the processes are not clear. (50 Food program)

The only area I would like to improve is the communication over contracts. Some of the information seems out of date or not relevant. We would also like earlier communication. Also knowing who to communicate with. (6 Food program)

\section{Mission-Related Issues}

About $28 \%$ of the responses focused on mission-related issues when commenting on their relationship with the central food bank. This included supporting their own particular mission, or expanding the reach of what they do.

Without them we could not feed the people we do.

(41 Food pantry)

The food bank helps us feed our members two meals a day, six days a week. The majority of our members are low income and/or homeless and would not have 
access to healthy and nutritious meals otherwise. (52 Food program)

The food bank delivering food to us helps us to complete our mission to serve the immediate community with physical needs and gives us a chance to minister to spiritual needs. (45 Food pantry)

Agencies were also concerned with reaching more people, focusing on nutrition, and having a greater impact.

We used to provide an additional food program for women with children over 5 years. The funding changed and we had to stop doing it. We would have liked to continue to offer it. (34 Food program)

The variety (more nutritious aspects such as beans, rice, juices) is probably more important as we don't get these in our own donations. (16 Food bank)

Maybe something to offer on a year-round basis ' not necessarily feeding but something along those lines. They bring food during the summer. Maybe at other times a voucher could be used? (100 Food program)

\section{Collaboration Issues}

Finally, about $18 \%$ of the responses focused on issues related to collaboration. These related to working together to come up with ways of 'shortening the line' through providing holistic services and training for future employment. Other comments related to working together to coordinate activities to maximize impact, or to build capacity.

We all work with same clients across the agencies. We refer between each other" and I would like to see wrap around service expanded so that referral process is stronger. (24 Food program)

Because of the nature of my school many kids won't go to college. The food bank has a training program and maybe we could partner with them for our students. (103 Food program)

We send them stuff and they send us stuff. We have a lot of lettuce here. They have a lot of product and do well. They are very generous in offering their staff to give us support as needed. (5 Food bank)

If they could help us write a grant to get the cold storage. It is mostly cold storage but if we could keep items longer. With the mobile pantry everything has to be distributed on the spot. (3 Food pantry)

Getting a larger warehouse we could handle receiving more food and then we could distribute it to the other foodbanks. We discussed the possibility in the past with the food bank and they were agreeable. (13 Food bank)

\section{Analysis}

\section{Method for Developing Taxonomy of Accountability Relationships}

Building on the concepts of business and social partnerships (Waddock 1989; Wilson et al. 2010), a schema of partnership dynamics was developed to isolate expectations of accountability. Three 'ideal' relationship types were proposed based on an intercoder process involving the authors reviewing and discussing each of the interview findings along with profile of the agency's together to find common patterns related to the nature of the partnership between the partner and food bank. More specifically, patterns were discussed along the following lines: how much the agency received from the food bank and interpretations of the strength or weakness of their relationship with the food bank. Overall, what the discussion revealed was that patterns fell into three basic relationship categories. The first is a supplier-customer relationship, where the agencies saw themselves as 'customers' of the food bank and thus were primarily concerned with the product received and the processes involved in getting that product, which creates a more transactional connection. The second is a supporter-customer relationship, where the agency was concerned with not only the business aspects of the transaction (product and process), but also felt supported in achieving and collaborating to fulfill its social impact, and therefore engage in transformational activity. The third type is supporter-collaborator, where the agency sees itself working collaboratively with the food bank to achieve a common mission, which is also consistent with transformational action. In other words, the first term (supplier, supporter) refers to how the food pantry views the role of the food bank, and the second term (customer, collaborator) to how the food pantry views their role in relation to the food bank. Next we describe how each agency was subsequently coded and categorized into each category.

\section{Relationship Categorization Based on Agency Categorization}

Using this framework, we went back to the data and coded the agencies according to these three relationship types. Those with primary concerns about products or operations were coded as having a supplier-customer relationship. Those who had concerns about both products and 
operations as in a business partnership, and mission impact and collaboration as in a social partnership were coded as having a supporter-customer relationship. Those with concerns solely regarding mission impact or collaboration were coded as having a supporter-collaborator relationship. As a result, thirty-eight percent were identified as having a supplier-customer relationship; one-third as having a supporter-customer relationship; and $30 \%$ as having a supporter-collaborator relationship. The primary areas of concern of these groups based on the themes identified previously are shown in Table 3.

We then ran several analyses using SPSS, including cross-tabulations (Chi-square statistic) and a one-way ANOVA, to see whether there was any relationship between accountability type and other factors that might provide further insights into the food bank-agency partner network. A summary of those results is provided in Table 4.

The one-way ANOVA resulted in a statistically significant difference among the three accountability types between the average annual pounds of food processed by the organizations, $\mathrm{F}(2,58)=4.059, p=.022$. There was no significant difference when comparing the length of relationship with the food bank. To look at whether accountability type differed according to the mission focus or type of organization, a Chi-square statistic was conducted. The Pearson Chi-square results indicated that both mission $\left(x^{2}=8.56, d f=2, N=61, p=.014\right)$ and type $\left(x^{2}=12.04, d f=4, N=61, p=.017\right)$ differed significantly by accountability type. Thus, relationships were found between the number of pounds of food provided by the food bank to the agency, the focus of the agency mission, and the type of agency organization. There was no relationship between the length of time the agencies had interacted with the food bank.

Table 3 Primary concerns by relationship type

\begin{tabular}{llll}
\hline & $\begin{array}{l}\text { Business- } \\
\text { customer } \\
(n=23, \\
38 \%)\end{array}$ & $\begin{array}{l}\text { Supplier- } \\
\text { customer } \\
(n=20, \\
33 \%)\end{array}$ & $\begin{array}{l}\text { Supporter- } \\
\text { collaborator } \\
(n=18, \\
30 \%)\end{array}$ \\
\hline Product & 9 & 0 & 0 \\
Operations & 6 & 0 & 0 \\
Product/operations & 8 & 0 & 0 \\
Product/mission & 0 & 8 & 0 \\
Product/collaboration & 0 & 5 & 0 \\
Operations/mission & 0 & 4 & 0 \\
Operations/collaboration & 0 & 3 & 0 \\
Mission & 0 & 8 & 12 \\
Collaboration & 0 & 12 & 1 \\
Mission/collaboration & 0 & 0 & 5 \\
\hline
\end{tabular}

Identified strengths and weaknesses reflect a set of relationship expectations established by the partner agency as well as criteria to determine how well those expectations are met by the food bank. In essence, this can be used to translate into how well or poorly the food bank meets accountability expectations of the member agency. In particular, accountability expectations address how well the lead agency helps the member agency with providing quality food that fits their needs (product), the reliability and ease of provision to their needs (operational issues), and the ability to achieve their mission and the wider societal issue at hand. Given that the nature of this work is exploratory and grounded, we would be remiss to present the proposed typology as exhaustive of all food bank relationships, given that this is based on a single case study. Rather, they are reflective of this particular case context and are presented as a starting point for further inquiry. The research also leads to a number of propositions for further testing, which are presented next.

The type of accountability expressed by the member agencies varies with each relationship type with the lead agency. These findings provide a useful foundation for propositions worth exploration in the future. These propositions, which are listed below, reflect the nuanced nature of accountability within a single network and how it may impact the productivity of a partnership in the context of key network dynamics.

Proposition 1 Within a single network, variations of accountability result from the expected use and level of use of resources, and characterize the type of the relationship between member and lead agency.

A lead agency should take care to not necessarily assume that all types of capital available it has are valued the same way by all member agencies. While a lead agency may have capacity and expertise unrelated to the purview of its specialty and primary mission, not every network member agency may derive value from such organizational resources. Member agencies having a more transactional relationship (e.g., supplier-customer) with a lead agency value high accountability (i.e., expecting the food bank to perform strongly and meet expectations) in resource provision and communication. However, member agencies with a more transformational relationship (e.g., collaborative) value high accountability in areas where both parties support each other in capacity and resources. Exploring this proposition can help lead agencies can facilitate network management by encouraging a more strategic and efficient approach in how the lead agency develops and allocates certain types of capital and capacity. The differences in what member agencies value in accountability can also result in a more multi-dimensional assessment of success within a single network. 
Table 4 Factors related to accountability type

\begin{tabular}{llll}
\hline & $\begin{array}{l}\text { Supplier-customer } \\
(n=23,38 \%)\end{array}$ & $\begin{array}{l}\text { Supporter-customer } \\
(n=20,33 \%)\end{array}$ & $\begin{array}{l}\text { Supporter-collaborator } \\
(n=18,30 \%)\end{array}$ \\
\hline Average annual pounds of food* & 71,795 & 92,758 & 293,218 \\
Length of relationship with food bank n.s. (years) & 6.8 & 4.7 & 7.5 \\
Mission* & & & 56 \\
Food-related (\%) & 28 & 17 & 19 \\
Multifaceted (\%) & 42 & 40 & 71 \\
Type* & & & 50 \\
Food bank (\%) & 14 & 14 & 17 \\
Food pantry (\%) & 33 & 41 & \\
Food program within agency (\%) & 43 & 47 \\
\hline
\end{tabular}

$* p<.05$

Moving forward, research addressing this proposition could focus on how the nature of relationships and accountability would vary based on the availability of resources throughout a certain time frame. For example, in times of austerity (e.g., minimal donations), would money or food be more valuable and shape the nature of accountability within a network?

Proposition 2 Expectations of accountability by a member agency for the lead agency within a collaborative network derive from the specific type of relationship the member agency has of the lead agency.

An array of network structural taxonomies exists that can offer choices of how lead agencies may approach driving nature of relationships with member agencies (Agranoff and McGuire 2004; Dawes and Eglene 2004; Guo and Acar 2005). While there is some benefit and even expectation for lead agencies to dictate the nature of their relationship with member agencies with a single approach, inefficient outcomes may arise due to a misalignment of expectations. This proposition implies that a lead agency may need to be flexible with multiple management and governance approaches based on having various types of partnerships within a single network based on how it will be held accountable by different members.

Future research could explore how expectations of the lead agency may change over time, particularly if the member agency is part of another network where they are receiving similar kinds of support.

Proposition 3 The type of accountability (i.e., business or social) expected by the member agency requires that lead agencies take different approaches to managing its relationship with the member agency in order to maintain high accountability.
While debates continue about the valid distinction between management and leadership, some validation exists justifying how such a distinction can support addressing different aspects of network dynamics (McGuire and Silvia 2009). To reiterate, business accountability reflects a transactional relationship characterized by a supplier-customer dynamic focused on the acquisition and distribution of resources; social accountability focuses on obtaining and distributing resources for the purpose of social impact (i.e., mission implementation). Addressing areas of accountability identified in suppliercustomer relationships will likely benefit from managerial solutions focused on day-to-day operational tasks such as improving communication practices. Both leadership and managerial actions can address accountability concerns for supporter-customer relationships such as identifying and securing better and more varied primary resources. For collaborator relationships, accountability requires application of leadership behaviors such as decision making, visioning, and strategizing.

Future research could explore the presence of additional types of accountability. For example, while financial capital is certainly critical, a lead agency providing social capital in the form of connecting with other agencies could be important as well to gain access to other resources, which may portend another kind of accountability and expectations.

\section{Conclusion}

Using an inductive approach to cull through interview data of food bank partners, this paper sought to understand perceptions of accountability in various types of collaborations among food banks and pantries. By exploring 
partner agencies understandings of accountability, we discovered how various expectations on behalf of the partner organizations reflected the presence of several types of relationships: supplier-customer, supporter-customer, and supporter-collaborator. Furthermore, these expectations of how organizations want to be supported and interacted with illustrate key partnership dynamics. These dynamics include the presence of a shared vision, resource provision, communication and relationship management. We find that each type of relationship manifests in different and similar ways along the lines of these dynamics. More specifically, relationships that are more transactional in nature tend to be characterized by higher degrees of one-way capacity building and resource provision, whereas relationships that are more collaborative in nature tend to be characterized by mutual exchanges of resources and capacity, which are bolstered by shared vision and stronger communication.

While these results are specific to one food bank alliance and are not necessarily generalizable to the broader populations, the dynamics present in the food bank partnerships used for this study seem to be consistent with already wellknown collaboration findings. In particular, these are the strengths of good communication; having a shared vision; leveraging and focusing on the strengths of collaborating agencies; and the need for consistent and strong engagement all make for fruitful collaborations. In this way, food bank networks are quite similar to other nonprofit collaborations.

A few of the weaknesses identified by the agencies are also consistent with what is known about poor agency collaboration. What was most interesting is the 'weakness in strength' dynamic whereby the findings suggest that the food bank suffers from not doing more of what it is good at. In essence, this means that when the food bank collaboration is doing well, an expectation is created among the partners that these behaviors will be enhanced. While this is reasonable, the danger lies in creating a strong dependency upon the food bank where mutual collaboration and responsibility are eroded. However, the fact that a fifth of the sample expressed interest in more collaboration opportunities involving the sharing of responsibilities indicates a desire for maintaining some shared power or responsibility in fulfilling the primary mission of mitigating food insecurity.

Related to the point above, this calls into question what specific benefits the food bank perceives it gets from partnering with the agencies and to what extent these benefits are recognized. This is important to realize since it can help partner agencies better understand how to align their strengths with food bank providing them with support. As mentioned before, it can be said that the agencies provide the food bank the opportunity to expand its reach in alleviating hunger and enabling secondary missions related to human welfare. It would be worthwhile to see whether this perspective is present among the food bank itself and how such a perspective influences its strategies for supporting and partnering with agencies. This may be a unique aspect of food bank collaborations in that enabling ancillary missions are critical among the collaborating agencies rather than focusing on just one primary mission.

The findings also suggest important implications for management and leadership for networks wishing to move from a supplier-customer relationship to more of a supporter-customer or supporter-collaborator relationship. In fact, effective communication and relationship management, and facilitating a shared vision are common collaborative management principles that can facilitate better resource provision and increased impact. Consistent, clear communication can facilitate a better understanding of expectations and the extent to which mission are mutually understood. Attention to relationship management (e.g., addressing needs and expectations of the member agency) can build trust and strength in a partnership, also resulting in better support and mission delivery.

Considering the aforementioned managerial benefits, managers at both a primary food bank and member agencies may want to consider the following guidelines to facilitate stronger partnerships: communication guidelines with details regarding various points of contact with appropriate information, appropriate mechanisms (e.g., email and personal phone calls), and frequency of interaction. Relationship management guidelines may include assessing the satisfaction with the partnership, conducting needs assessments, and addressing noted deficiencies. Facilitating a shared vision can be accomplished with jointly developing strategic objectives. Resource provision can be improved by developing guidelines for tracking and assessing the tangible and intangible resources used by the member agency, which would include the inputs needed to create and deploy them.

In closing, further research in this area could be conducted comparing agencies that rely heavily on the food bank for their food supply, versus those that have a variety of other suppliers. Additionally, a study exploring the perspective of the food bank would also add to this area of knowledge - particularly the extent to which they practice the aforementioned (and other) managerial practices and how such practices are manifested according to various types of partnerships.

\section{Compliance with Ethical Standards}

Conflict of interest The authors declare that they have no conflict of interest.

Open Access This article is distributed under the terms of the Creative Commons Attribution 4.0 International License (http:// 
creativecommons.org/licenses/by/4.0/), which permits unrestricted use, distribution, and reproduction in any medium, provided you give appropriate credit to the original author(s) and the source, provide a link to the Creative Commons license, and indicate if changes were made.

\section{References}

Acar, M., Guo, C., \& Yang, K. (2008). Accountability when hierarchical authority is absent: Views from public-private partnership practitioners. The American Review of Public Administration, 38(1), 3-23.

Agranoff, R., \& McGuire, M. (2004). Collaborative public management: New strategies for local governments. Washington, D.C.: Georgetown University Press.

Arya, B., \& Lin, Z. (2007). Understanding collaboration outcomes from an extended resource-based view perspective: The roles of organizational characteristics, partner attributes, and network structures. Journal of Management, 33(5), 697-723.

Austin, J. E. (2010). The collaboration challenge: How nonprofits and businesses succeed through strategic alliances. San Francisco, CA: Jossey Bass.

Axelsson, R., \& Axelsson, S. B. (2006). Integration and collaboration in public health-A conceptual framework. The International journal of health planning and management, 21(1), 75-88.

Baglioni, S., De Pieri, B., \& Tallarico, T. (2017). Surplus food recovery and food aid: The pivotal role of non-profit organisations. Insights from Italy and Germany. VOLUNTAS: International Journal of Voluntary and Nonprofit Organizations, 28(5), 2032-2052.

Baker, E., Kan, M., \& Teo, S. T. (2011). Developing a collaborative network organization: Leadership challenges at multiple levels. Journal of Organizational Change Management, 24(6), 853-875.

Bartczak, L. (2015). Building collaboration from the inside out. Washington, DC: Grantmakers for Effective Organizations.

Bazerghi, C., McKay, F. H., \& Dunn, M. (2016). The role of food banks in addressing food insecurity: A systematic review. Journal of Community Health, 41(4), 732-740

Berner, M. (2017). Multidimensional measures of poverty: The potential contribution of non-profit food pantry data to assess community economic condition. Poverty \& Public Policy, 9(4), 381-401.

Berner, M., \& O'Brien, K. (2004). The shifting pattern of food security support: Food stamp and food bank usage in North Carolina. Nonprofit and Voluntary Sector Quarterly, 33(4), 655-672.

Berner, M., Ozer, T., \& Paynter, S. (2008). A portrait of hunger, the social safety net, and the working poor. Policy Studies Journal, 36(3), 403-420.

Booth, S., \& Whelan, J. (2014). Hungry for change: The food banking industry in Australia. British Food Journal, 116(9), 1392-1404.

Broadbent, J., Dietrich, M., \& Laughlin, R. (1996). The development of principal-agent, contracting and accountability relationships in the public sector: Conceptual and cultural problems. Critical perspectives on accounting, 7(3), 259-284.

Campbell, E. C., Ross, M., \& Webb, K. L. (2013). Improving the nutritional quality of emergency food: A study of food bank organizational culture, capacity, and practices. Journal of Hunger \& Environmental Nutrition, 8(3), 261-280.

Candler, G., \& Dumont, G. (2010). A non-profit accountability framework. Canadian Public Administration, 53(2), 259-279.

Chaparro, M. P., Zaghloul, S. S., Holck, P., \& Dobbs, J. (2009). Food insecurity prevalence among college students at the University of Hawai'i at Mānoa. Public Health Nutrition, 12(11), 2097-2103.

Chen, B., \& Graddy, E. A. (2010). The effectiveness of nonprofit lead-organization networks for social service delivery. Nonprofit Management and Leadership, 20(4), 405-422.

Cohen, J. A. (2006). Ten years of leftovers with many hungry still left over: A decade of donations under the Bill Emerson Good Samaritan Food Donation Act. Seattle J. Soc. Just., 5, 455.

Cook, J. T., \& Frank, D. A. (2008). Food security, poverty, and human development in the United States. Annals of the New York Academy of Sciences, 1136(1), 193-209.

Curtis, K. A., \& McClellan, S. (1995). Falling through the safety net: poverty, food assistance and shopping constraints in an American city. Urban Anthropology and Studies of Cultural Systems and World Economic Development, 24(1), 93-135.

Daponte, B. O. (2000). Private versus public relief: Use of food pantries versus food stamps among poor households. Journal of Nutrition Education, 32(2), 72-83.

Daponte, B. O., \& Bade, S. (2006). How the private food assistance network evolved: Interactions between public and private responses to hunger. Nonprofit and Voluntary Sector Quarterly, 35(4), 668-690.

Dawes, S. S., \& Eglene, O. (2004). New models of collaboration for delivering government services: A dynamic model drawn from multi-national research. In Proceedings of the 2004 annual national conference on Digital government research (p. 93). Digital Government Society of North America.

Ebrahim, A. (2003). Accountability in practice: Mechanisms for NGOs. World Development, 31(5), 813-829.

Emerson, K., \& Nabatchi, T. (2015). Collaborative governance regimes. Washington, D.C.: Georgetown University Press.

Feeding America (2015). Our history. http://www.feedingamerica. org/about-us/about-feeding-america/our-history/?_ga=1. 163708343.909625620.1422398512 Accessed March 10, 2018.

Gardner, B., \& Director, H. R. (2011). Comprehensive community initiatives: Promising directions for "Wicked" problems? Horizons policy research initiative. Toronto: Welleslley Institute.

Gazley, B. (2010a). Linking collaborative capacity to performance measurement in government-nonprofit partnerships. Nonprofit and Voluntary Sector Quarterly, 39(4), 653-673.

Gazley, B. (2010b). Why not partner with local government? Nonprofit managerial perceptions of collaborative disadvantage. Nonprofit and Voluntary Sector Quarterly, 39(1), 51-76.

González-Torre, P. L., \& Coque, J. (2016). How is a food bank managed? Different profiles in Spain. Agriculture and Human Values, 33(1), 89-100.

González-Torre, P., Lozano, S., \& Adenso-Díaz, B. (2017). Efficiency analysis of the European food banks: Some managerial results. International Journal of Voluntary and Nonprofit Organizations, 28(2), 822-838

Gundersen, C., Brown, J., Engelhard, E., \& Waxman, E. (2011). Map the meal gap: Technical brief. Chicago, IL: Feeding America.

Guo, C., \& Acar, M. (2005). Understanding collaboration among nonprofit organizations: Combining resource dependency, institutional, and network perspectives. Nonprofit and Voluntary Sector Quarterly, 34(3), 340-361.

Handforth, B., Hennink, M., \& Schwartz, M. B. (2013). A qualitative study of nutrition-based initiatives at selected food banks in the feeding America network. Journal of the Academy of Nutrition and Dietetics, 113(3), 411-415.

Hill, C. J., \& Lynn, L. E. (2003). Producing human services: Why do agencies collaborate? Public Management Review, 5(1), 63-81.

Jordan, L. (2005). Mechanisms for NGO accountability. GPPi Research Paper Series, 3. https://www.files.ethz.ch/isn/15446/ NGO\%20Accountabiliy.pdf. 
Jyoti, D. F., Frongillo, E. A., \& Jones, S. J. (2005). Food insecurity affects school children's academic performance, weight gain, and social skills. The Journal of nutrition, 135(12), 2831-2839.

Kapucu, N. (2005). Interorganizational coordination in dynamic context: Networks in emergency response management. Connections, 26(2), 33-48.

Kapucu, N. (2006). Interagency communication networks during emergencies: Boundary spanners in multiagency coordination. The American Review of Public Administration, 36(2), 207-225.

Kapucu, N., Arslan, T., \& Demiroz, F. (2010). Collaborative emergency management and national emergency management network. Disaster Prevention and Management: An International Journal, 19(4), 452-468.

Koliba, C. J., Mills, R. M., \& Zia, A. (2011). Accountability in governance networks: An assessment of public, private, and nonprofit emergency management practices following Hurricane Katrina. Public Administration Review, 71(2), 210-220.

Lambie-Mumford, H. (2013). 'Every town should have one': Emergency food banking in the UK. Journal of Social Policy, 42(01), 73-89.

Larson, P. D., \& McLachlin, R. (2011). Supply chain integration under chaotic conditions: Not-for-profit food distribution. International Journal of Procurement Management, 4(3), 315-322.

McEntee, J. C., \& Naumova, E. N. (2012). Building capacity between the private emergency food system and the local food movement: Working toward food justice and sovereignty in the global North. Journal of Agriculture, Food Systems, and Community Development, 3(1), 235-253.

McGuire, M., \& Silvia, C. (2009). Does leadership in networks matter? Examining the effect of leadership behaviors on managers' perceptions of network effectiveness. Public Performance \& Management Review, 33(1), 34-62.

McIntyre, L., Lukic, R., Patterson, P. B., Anderson, L. C., \& Mah, C. L. (2016). Legislation debated as responses to household food insecurity in Canada, 1995-2012. Journal of Hunger \& Environmental Nutrition, 11(4), 441-455.

McPherson, K. (2006). Food insecurity and the food bank industry: Political, individual and environmental factors contributing to food bank use in Christchurch-A research review. Christchurch (NZ): University of Canterbury.

Mitchell, S. M., \& Shortell, S. M. (2000). The governance and management of effective community health partnerships: A typology for research, policy, and practice. The Milbank Quarterly, 78(2), 241-289.

Mohan, S., Gopalakrishnan, M., \& Mizzi, P. J. (2013). Improving the efficiency of a non-profit supply chain for the food insecure. International Journal of Production Economics, 143(2), $248-255$.

Mosley, J. E. (2010). Organizational resources and environmental incentives: Understanding the policy advocacy involvement of human service nonprofits. Social Service Review, 84(1), 57-76.

Orgut, I. S., Brock, L. G., III, Davis, L. B., Ivy, J. S., Jiang, S., Morgan, S. D., et al. (2016). Achieving equity, effectiveness, and efficiency in food bank operations: Strategies for feeding America with implications for global hunger relief. In C. W. Zobel, N. Altay, \& M. P. Haselkorn (Eds.), Advances in managing humanitarian operations (pp. 229-256). Cham: Springer.

Page, S. (2004). Measuring accountability for results in interagency collaboratives. Public Administration Review, 64(5), 591-606.

Paynter, S., \& Berner, M. (2014). Organizational capacity of nonprofit social service agencies. Journal of Health and Human Services Administration, 37(1), 111-145.

Paynter, S., Berner, M., \& Anderson, E. (2011). When even the 'Dollar Value Meal' costs Too much: Food insecurity and long dependence on food pantry assistance. Public Administration Quarterly, 35(1), 26-58.

Poppendieck, J. (2014). Food assistance, hunger and the end of welfare in the USA. In G. Riches \& T. Silvasti (Eds.), First world hunger revisited (pp. 176-190). London: Palgrave Macmillan.

Power, E. M. (1999). Combining social justice and sustainability for food security. In M. Koc (Ed.), For hunger-proof cities: sustainable urban food systems. Ottawa: International Development Research Centre.

Precious, C., Baker, K., \& Edwards, M. (2017). Coping with compassion: Role transformation amongst Oregon food pantry directors. VOLUNTAS: International Journal of Voluntary and Nonprofit Organizations, 28(5), 2011-2031.

Proulx, K., Hager, A., \& Klein, K. C. (2014). Models of collaboration between nonprofit organizations. International Journal of Productivity and Performance Management, 63(6), 746-765.

Remley, D. T., Kaiser, M. L., \& Osso, T. (2013). A case sudy of promoting nutrition and long-term food security through choice pantry development. Journal of Hunger \& Environmental Nutrition, 8(3), 324-336.

Riches, G. (2002). Food banks and food security: Welfare reform, human rights and social policy. Lessons from Canada? Social Policy \& Administration, 36(6), 648-663.

Schmidhuber, J., \& Tubiello, F. N. (2007). Global food security under climate change. Proceedings of the National Academy of Sciences, 104(50), 19703-19708.

Second Harvest Food Bank of Northwest North Carolina (2015). The history of Food Banking. Retrieved October 24, 2018 http:// www.hungernwnc.org/about-us/history\%20of\%20food\%20bank ing.html.

Selden, S. C., Sowa, J. E., \& Sandfort, J. (2006). The impact of nonprofit collaboration in early child care and education on management and program outcomes. Public Administration Review, 66(3), 412-425.

Sharma, S., Helfman, L., Albus, K., Pomeroy, M., Chuang, R. J., \& Markham, C. (2015). Feasibility and acceptability of brighter bites: A food co-op in schools to increase access, continuity and education of fruits and vegetables among low-income populations. The Journal of Primary Prevention, 36(4), 281-286.

Snavely, K., \& Tracy, M. B. (2000). Collaboration among rural nonprofit organizations. Nonprofit Management and Leadership, 11(2), 145-165.

Sowa, J. E. (2009). The collaboration decision in nonprofit organizations: Views from the front line. Nonprofit and Voluntary Sector Quarterly, 38(6), 1003-1025.

Sparks, R., Rumer, T., Boyd, K., \& Culbertson, M. (2018). Understanding food pantry/partner needs of Midwest food bank. In University Research Symposium (p. 142). https://ir.library. illinoisstate.edu/rsp_urs/142.

Tarasuk, V., Dachner, N., \& Loopstra, R. (2014). Food banks, welfare, and food insecurity in Canada. British Food Journal, 116(9), 1405-1417.

Tarasuk, V., \& Eakin, J. M. (2005). Food assistance through "surplus" food: Insights from an ethnographic study of food bank work. Agriculture and Human Values, 22(2), 177-186.

Temporary Emergency Food Assistance Act of 1983, P.L. 98-8, 97 Stat. 35 (1983).

Turrini, A., Cristofoli, D., Frosini, F., \& Nasi, G. (2010). Networking literature about determinants of network effectiveness. Public Administration, 88(2), 528-550.

Vernis, A., Iglesias, M., Sanz, B., \& Saz-Carranza, A. (2006). Nonprofit Organizations: Challenges and collaboration. New York, NY: Palgrave Macmillan. 
Waddock, S. (1989). Understanding social partnerships: An evolutionary model of partnership organizations. Administration and Society, 21(1), 78-100.

Waugh, W. L., Jr., \& Streib, G. (2006). Collaboration and leadership for effective emergency management. Public Administration Review, 66, 131-140.

Weber, E. P., \& Khademian, A. M. (2008). Wicked problems, knowledge challenges, and collaborative capacity builders in network settings. Public Administration Review, 68(2), 334-349.

Weinfield, N.S., Mills, G., Borger, C., Gearing, M., Macaluso, T., Montaquila, J., \& Zedlewski, S. (2014). Hunger in America 2014: National Report Prepared for Feeding America. Retrieved October 24, 2018 from http://help.feedingamerica.org/Hunger InAmerica/hunger-in-america-2014-full-report.pdf.
Wilson, E. J., Bunn, M. D., \& Savage, G. T. (2010). Anatomy of a social partnership: A stakeholder perspective. Industrial Marketing Management, 39(1), 76-90.

Yin, R. K. (2014). Case study research: Design and methods (5th ed.). Thousand Oaks, CA: Sage Publications.

Young, D. R. (2000). Alternative models of government-nonprofit sector relations: Theoretical and international perspectives. Nonprofit and Voluntary Sector Quarterly, 29(1), 149-172.

Zaheer, A., \& Harris, J. (2006). Interorganizational trust. In O. Shenkar \& J. Reuer (Eds.), Handbook of strategic alliances (pp. 169-197). Thousand Oaks, CA: Sage Publications.

Publisher's Note Springer Nature remains neutral with regard to jurisdictional claims in published maps and institutional affiliations. 